\title{
DESAIN BAHAN AJAR MATAKULIAH PENDIDIKAN AGAMA ISLAM DENGAN PENDEKATAN INTEGRATIF-INTERKONEKTIF ANTARA RELIGIOUS STUDIES, NATURAL SCIENCES, SOCIAL SCIENCES, DAN HUMANITIES
}

\author{
Yusuf Hanafi \\ Fakultas Sastra, Universitas Negeri Malang; sufirmi@yahoo.com
}

Diterima: 30 Juni 2016. Disetujui: 29 Oktober 2016. Dipublikasikan: Desember 2016

\begin{abstract}
Dicotomy differentiation between religious and general studies affected islamic studies become stiff and rigid. So it is less responsive to the challenge and demand of developing era. This research is aimed to arrange a new handbook of Islamic education which is spirited by ethos and breath of reintegrative epistemology between religious studies and general studies, such as: natural sciences, social sciences, and humanities. Meanwhile the result targeted of this research is: (1) a new islamic education syllabus which is balance with principals of islamic studies through integrative-interconnective approach (interdisciplinary); (2) A new islamic education handbook with integrative-interconnective approach which is accepted both theoretically and practically; (3) The design of Islamic education's teaching plan in one semester presented in 16 meetings which is tested in teaching and learning process; (4) Islamic education's teaching scenario through a new teaching material which is able to implement the mission of islamic studies interdisciplinarily.
\end{abstract}

\begin{abstract}
Abstrak
Pemilahan secara dikotomis terhadap studi agama dan studi umum menjadi sulit dan kaku. Sehingga kurang responsif terhadap tantangan dan permintaan pengembangan era. Penelitian ini bertujuan untuk membuat ulang buku pegangan baru pendidikan Islam yang berenergioleh etos dan napas epistemologi baru antara studi agama dan studi umum, seperti: ilmu alam, ilmu sosial, dan humaniora. Sementara itu hasil yang ditargetkan dari penelitian ini adalah: (1) silabus pendidikan Islam baru yang seimbang pada prinsip studi Islam melalui pendekatan integratif-interkonektif (interdisipliner); (2) sebuah buku pegangan pendidikan islamyang baru dengan pendekatan integratif-interkonektif yang dapat diterima baik secara teoritis dan praktis; (3) Rancangan rencana pengajaran pendidikan Islam dalam satu semester disajikan dalam 16 pertemuan yang diuji dalam proses belajar danproses pengajaran; (4) Skema pengajaran pendidikan Islam melalui bahan pengajaran baru yang mampu melaksanakan misi studi Islam dengan lintas disiplin.
\end{abstract}

Keywords: Islamic education, integrative-interconnective approach, reintegrative epistemology between religious and general studies.

(C) 2016 URPI, FTK IAIN Raden Intan Lampung

\section{PENDAHULUAN}

Terobosan pengkajian ilmu-ilmu keislaman secara interdisipliner yangdiangkat melalui penelitian iniberangkatdari keinsyafan bahwa pada hakikatnya antarberbagai bidang keilmuan itu saling memiliki keterkaitan, karena memang yang dibidik oleh seluruh disiplin keilmuan adalah realitas alam semesta yang sama, hanya saja dimensi dan fokus perhatian yang dilihat oleh masing-masing disiplin itu berbeda. Oleh karena itu, superioritas, ekslusivitas, pemilahan secara dikotomis terhadap bidang-bidang keilmuan tertentu hanya akan merugikan bidang ilmu itu sendiri, baik secara psikologis maupun ilmiah-akademis. Betapapun setiap bidang ilmu tentunya ingin menyuguhkan kajian yang lebih utuh dan komprehensif, bukannya sajian yang parsial dan reduktif. Dengan menimbang asumsi ini, setiap ilmuwan perlu memiliki visi integrasiinterkoneksi. Mengkaji satu bidang keilmuan dengan memanfaatkan bidang keilmuan lain itulah "integrasi", dan melihat kesalingterkaitan antar berbagai disiplin ilmu itulah "interkoneksi" 
(Abdullah, 2001, 2006).

Ironisnya, silabus matakuliah Pendidikan Agama Islam (PAI) yang dikembangkan di Perguruan Tinggi Umum (PTU) justru mencerminkan paradigma dikotomisatomistik.Karenanya, kesadaran untuk membenahi dan menyembuhkan "lukaluka dikotomi" keilmuan agama dan keilmuan umum yang makin hari kian menyakitkan merupakan tuntutan yang mendesak. Proyek reintegrasi epistemologi keilmuan agama dan keilmuan umum mengandung arti perlunya dialog dan kerjasama antara disiplin ilmu agama dan ilmu umum yang lebih erat di masa yang akan dating(Abdullah, 2007). Pendekatan interdiciplinary dikedepankan, interkoneksitas dan sensitivitas antarberbagai disiplin ilmu agama (religious studies)dengan disiplin ilmu kealaman (natural sciences), disiplin ilmu sosial (social sciences), dan disiplin ilmu humaniora (humanities)perlu diupayakan secara terus-menerus tanpa henti(Mansoer, 2006).

Bukan eranya lagi disiplin ilmu agama (Islam) menyendiri dan steril dari kontak dan intervensi ilmu-ilmu kealaman, ilmu-ilmu sosial, dan humaniora. Studi tentang agama (termasuk matakuliah PAI di PTU) akan sungguh-sungguh menderita, jika pandangan-pandangan dan analisisanalisisnya tidak memahami, mempertimbangkan atau menyertakan sama sekali bagaimana sesungguhnya diskursus tentang politik, ekonomi, sosial, budaya, dan seni(Shahrur, 1990). Sebab aspek-aspek tersebut memiliki pengaruh yang luar biasa terhadap tampilan matakuliah PAI, dan begitu pula sebaliknya(Rahman, 1982)

Berpijakataskerangka berpikir tersebut, penelitian yang berwujud pengembangan buku ajar matakuliah PAI di PTU ini teramat mendesak untuk dilakukan. Penelitian ini mengkaji untuk selanjutnya mengembangkan buku ajar matakuliah PAI di Universitas Negeri Malang (UM), yakni buku "Reorientasi Pendidikan Islam: Menuju Pengembangan Kepribadian Insan Kamil"dengan pendekatan integratifinterkonektif seperti telah diuraikan di atas. Berdasarkan telaah peneliti sebelumnya, bangunan epistemologi keilmuan dan beberapa bagian materinya sangat kentara dikonstruksi secara dikotomisdengan model kajian single entity atau setidaknya isolated entities (padahal idealnya: interconected entities).

UM sebagai PTU yang menyelenggarakan layanan akademis untuk seluruh bidang disiplin keilmuan modern (eksakta, sosial, dan humaniora) jelas merupakan laboratorium yang tepat untuk menggodok proyek reintegrasi epistemologi keilmuan agama dan keilmuan umum yang luaran penelitiannya nanti berbentuk buku ajar ini. Di samping UM sendiri secara kelembagaan tentunya sangat berharap agar sajian matakuliah PAI (yang termasuk rumpun Matakuliah Pengembangan Kepribadian [MPK]dalam kurikulum inti dan diajarkan di semua fakultas) dapat menyentuh dan menyapasecara metodologis disiplin keilmuan para peserta didiknya yang beragam,sehingga pada gilirannya mereka dapat merasakankebermaknaannya, baik dalam proses belajar-mengajar di kelasmaupun saat memasuki dunia kerja kelak.

\section{PEMBAHASAN}

\section{A. Fokus dan Metode Penelitian}

Tujuan yang hendak dicapai melalui program pengembanganini adalah tersusunnya buku ajar matakuliah PAI baru yang dijiwai oleh etos dan nafas reintegrasi epistemologi keilmuan agama (religious studies) dankeilmuan umum (natural sciences, social sciences dan humanities). 
Secara khusus, pengembangan inibertujuan untuk: (1) menyempurnakan silabus matakuliah PAI baru agar selaras dengan prinsip-prinsip pengkajian ilmuilmu keislaman secara interdisipliner; (2) mengujicobakan buku ajar matakuliah PAI baru yang telah dikembangkan dengan pendekatan integratif-interkonektif agar nantinya menjadi produk yang reliable dan berterima, baik secara teoritis maupun praktis; (3) menyempurnakan desain Rencana Perkuliahan Semester (RPS) matakuliah PAI untuk disajikan dalam satu semester penuh sekaligus mengevaluasiefektivitasnya dalam mengimplementasikan misi pengkajian ilmu-ilmu keislaman secara interdisipliner; dan (4) menyempurnakan skenario pembelajaran matakuliah PAI dengan buku ajar PAI baru yang dikembangkan dengan pendekatan integratif-interkonektif (interdisipliner)(Baum, 1999).

Pada penelitian tahap akhir ini, digunakan desain penelitian pengembangan yang dilanjutkan ke penelitian eksperimental. Pasalnya, kegiatan pada tahun kedua ini lebih didominasi oleh uji coba produk dan perbaikan draft materi yang telah disusun pada tahun pertama setelah mendapatkan input dari para pakar dan pengguna buku ajar PAI (baca: mahasiswa). Desain penelitian pengembangan ini digunakan untuk menyempurnakan(Kuntowijoyo, 2007): (1) silabus matakuliah PAI baru agar selaras dengan prinsip-prinsip pengkajian ilmu-ilmu keislaman secara interdisipliner; (2) Rencana Perkuliahan Semester (RPS) matakuliah PAI untuk disajikan dalam satu semester penuh; (3) skenario pembelajaran matakuliah PAI dengan buku ajar PAI baru. Sedangkan desain penelitian eksperimental digunakan untuk mengujicobakan buku ajar matakuliah PAI baru agar nantinya menjadi produk yang reliable dan berterima, baik secara teoritis maupun praktis.

\section{B. Kerangka Buku Ajar Mata Kuliah Pendidikan Agama Islam}

Pengembangansilabus matakuliah PAI ini tidak sepenuhnya berangkat dari nol, akan tetapi merupakan pengembangan dari Silabus dan Rencana Perkuliahan Semester (RPS) yang sudah ada sebelumnya (Katalog UPMU, 2009). Di sini, silabus dikembangkan berdasarkan pendekatan kompetensi. Sebagaimana lazimnya silabus berbasis kompetensi, maka silabus hasil pengembangan ini nantinya terdiri atas: standar kompetensi, kompetensi dasar, indikator, tema, strategi, media, penilaian, dan alokasi waktu. Pensahihan silabus dilakukan melalui diskusi dengan pakar pengajaran matakuliah Pendidikan Agama Islam (para dosen PAI UM) dalam forum seminar kolegial.

Dalam sub bahasan ini, akan dipaparkan garis-garis besar perkuliahan berikut silabus matakuliah PAI yang meliputi tujuan umum, topik bahasan, dan garis-garis besar perkuliahan.

\section{Tujuan Umum Perkuliahan}

Tujuan umum perkuliahan PAI ini adalah agar mahasiswa memahami dan meyakini kebenaran berbagai aspek ajaran Islam, mengintegrasikannya dalam disiplin ilmu masing-masing secara interdisipliner, dan mengaplikasikannya dalam bentuk kepribadian dan tingkah laku sehari-hari.

\section{Topik Bahasan}

a. Prinsip-Prinsip Akidah Islam

(1) Kebutuhan dan Fitrah Manusia terhadap Tuhan

(2) Tauhid dan Macam-macamnya

(a) Definisi Tauhid

(b) Macam-Macam Tauhid

(3) Syirik dan Macam-Macamnya

(a) Definisi Syirik

(b) Macam-Macam Syirik

(4) Pembuktian Wujud Allah

(a) Pandangan Filsafat Islam

(b) Pandangan Sains 
(5) Perbandingan Agama-agama (Muqaranah al-Adyan)
(a) Yudaisme
(b) Kristen
(c) Islam

b. Konsepsi Islam tentang Manusia

(1) Konsepsi tentang Manusia

(a) Hakikat Manusia

(b) Potensi Manusia

(c) Persamaan dan Perbedaan Manusia dengan Makhluk Lain

(2) Kedudukan dan Tujuan Penciptaan Manusia

(a) Tujuan Penciptaan Manusia

(b) Fungsi dan Peranan yang Diberikan Allah kepada Manusia

(c) Tanggung Jawab Manusia sebagai Khalifah dan Hamba Allah

c. Hukum Islam, Aspek, dan Dimensinya

(1)Konsep Hukum Islam

(a) Pengertian Syariat dan Fikih

(b) Ragam Pemahaman Fikih

(2) Sumber Hukum Islam
(a) Al-Qur'an
(b) Hadis
(c) Ijtihad

(3) Prinsip Hukum Islam

(4) Hukum Islam dalam Struktur Perundang-undangan di Indonesia
(a) Kompilasi Hukum Islam (KHI)
(b) UU Pernikahan Nomor 1 Tahun 1974

(5) Perbandingan Mazhab
(a) Perbedaan adalah Rahmat
(b) Menyikapi Perbedaan Pendapat (Fiqh al-Ikhtilaf)

d. Etika, Moral, dan Akhlak dalam Perspektif Islam, serta Peranannya dalam Pembinaan Masyarakat

(1) Pengertian Etika, Moral, dan Akhlak

(2) Karakteristik Akhlak Islam
(3) Proses Pembentukan Akhlak

(4) Ruang Lingkup Akhlak Islam
(a) Akhlak kepada Allah SWT dan Rasul Allah SAW
(b) Akhlak kepada Sesama Manusia
(c) Akhlak terhadap Lingkungan

(5) Hubungan Tasawuf dengan Akhlak
(a) Konsep Tasawuf
(b) Proses Penyucian Diri (Takhalli, Tahalli, dan Tajalli)

(6) Peranan Akhlak dalam Pembinaan Masyarakat

e. Kebudayaan dan Peradaban Islam: Antara Sejarah Masa Lampau dan Harapan Masa Depan

(1) Konsep Kebudayaan dan Peradaban dalam Islam

(2) Karakteristik Kebudayaan dan Peradaban Islam

(3) Periodisasi Sejarah Kebudayaan dan Peradaban Islam

(4) Pasang-Surut Kebudayaan dan Peradaban Islam

(5) Masjid dan Madrasah Sebagai Pusat Kebudayaan dan Peradaban Islam

(6) Nilai-Nilai Islam dalam Kebudayaan Indonesia

f. Masyarakat Madani: Rekonstruksi Kehidupan Islami yang Ideal

(1) Sejarah dan Pemaknaan Masyarakat Madani

(2) Masyarakat Madani dalam Perspektif Islam

(3) Persyaratan Menuju Masyarakat Madani
(a) Persyaratan Lahiriah
(b)Persyaratan Batiniah

(4) Peluang dan Tantangan Menuju Masyarakat Madani

g. Respons Islam terhadap Politik, HAM, dan Demokrasi

(1) Pengertian Politik Islam 

(a) Perspektif Al-Qur'an tentang Politik- Pemerintahan

(b) Variasi Pandangan Umat Islam dalam Melihat Relasi Islam dan Politik

(c) Institusi Khilafah dalam Tradisi Politik Islam

(2) Prinsip-prinsip Dasar dan Citacita Politik Islam

(3) Prinsip-prinsip Politik Luar Negeri dalam Islam
(a) Etika Bertetangga dengan Baik
(b) Hubungan Internasional

(4) Demokrasi dalam Islam
(a) Konsep dan Sejarah Demokrasi
(b) Sisi Positif dan Negatif Demokrasi
(c) Pandangan Islam tentang Demokrasi

(5) Hak dan Kewajiban Asasi Manusia Menurut Islam

(a) Pengertian HAM dan KAM

(b) HAM menurut Piagam PBB

(c) Pandangan Islam tentang HAM dan KAM

h. Reformulasi Konsep Jihad Menuju Islam Moderat

(1) Pengertian Jihad dan Radikalisme Umat Beragama

(2) Landasan dan Macam-Macam Jihad

(3) Latar Belakang Radikalisme Agama

(4) Bentuk dan Dampak Radikalisme Umat Beragama

(5) Upaya Menanggulangi

Radikalisme Umat Beragama

(6) Muslim Moderat

i. Perempuan dan Feminisme dalam Islam
(1) Pengertian dan Sejarah Feminisme
(2) Jenis-jenis Feminisme
(3) Respons Masyarakat Muslim
(4) Konsep Islam Perempuan
(5) Pandangan Islam terhadap Feminisme

\section{Sajian Tiap Pertemuan}

Matakuliah PAI pada umumnya disajikan di semester-semester awal (I dan II), meski ada berberapa fakultas yang menyajikannya di semester-semester pertengahan (III, IV, V, dan VI).Matakuliah PAI berbobot 2 SKS.Dalam hitungan efektif, dalam 1 semester terdapat 16 pekan perkuliahan.Karenanya, pokok bahasan dalam buku ajar PAI didesain untuk disajikan dalam 16 kali tatap muka (minus 2 pertemuan untuk Ujian Tengah Semester dan Ujian Akhir Semester).

Rinciannya adalah sebagai berikut: (a) Prinsip-prinsip akidah Islam [2 x 100 menit]; (b) Konsepsi Islam tentang manusia $\left[\begin{array}{lllll}1 & \mathrm{x} & 100 & \text { menit}\end{array}\right]$ (c) HukumIslam, aspekdandimensinya [2 $\mathrm{x}$ 100 menit]; (d) Etika, moral, dan akhlak dalam perspektif Islam,serta peranannya dalam pembinaan masyarakat $\left[\begin{array}{lll}1 & \mathrm{x} & 100\end{array}\right.$ menit]; (e) Kebudayaan dan peradaban Islam: antara sejarah masa silam dan harapan masa depan [1 x 100 menit]; (f) Masyarakat madani, rekonstruksi kehidupan islami yang ideal $\left[\begin{array}{lll}2 & \mathrm{x} & 100\end{array}\right.$ menit]; (g) Respons Islam terhadap politik, demokrasi, dan HAM [2 x 100 menit]; (h) Reformulasi konsep jihad menuju Islam moderat [2 x 100 menit]; (i) Perempuan dalam Islam, menafsirkan kembali doktrin agama tentang perempuan [1 x 100 menit].

\section{BahanAjar Matakuliah Pendidikan Agama Islam dengan Pendekatan Integratif-Interkonektif \\ 1. Deskripsi Bahan Ajar}

Bahan ajar PAI yang substansinya dikembangkan secara interdisipliner ini terdiri atas sembilan bab. Deskripsi selengkapnya dapat dilihat pada tabel : 


\begin{tabular}{|c|c|c|c|c|c|}
\hline $\begin{array}{l}\text { Per- } \\
\text { tmn }\end{array}$ & $\begin{array}{c}\text { TEMA } \\
\text { Bahasan }\end{array}$ & POKOK Bahasan & $\begin{array}{c}\text { KOMPETENSI } \\
\text { Dasar }\end{array}$ & $\begin{array}{l}\text { INDIKATOR } \\
\text { Pencapaian } \\
\end{array}$ & $\begin{array}{l}\text { KEGIATAN } \\
\text { Perkuliahan }\end{array}$ \\
\hline 01 & $\begin{array}{l}\text { Prinsip- } \\
\text { prinsip } \\
\text { Akidah } \\
\text { Islam }\end{array}$ & $\begin{array}{l}\text { a. Kebutuhan dan } \\
\text { Fitrah Manusia } \\
\text { terhadap Tuhan } \\
\text { b. Tauhid dan } \\
\text { Macam- } \\
\text { macamnya } \\
\text { c. Syirik dan } \\
\text { Macam- } \\
\text { macamnya }\end{array}$ & \begin{tabular}{lr}
\multicolumn{2}{l}{ Memahami } \\
kebutuhan & dan \\
fitrah & manusia \\
terhadap & Allah \\
SWT, & serta \\
meyakini & \\
konsepsi & Islam \\
tentang & tauhid, \\
syirik, & dan \\
ragamnya &
\end{tabular} & $\begin{array}{l}\text { - Mendeskripsi-kan } \\
\text { kebutuhan dan } \\
\text { fitrah manusia } \\
\text { terhadap Allah } \\
\text { SWT; } \\
\text { - Mengimani } \\
\text { konsep keesaan } \\
\text { Allah SWT } \\
\text { (tauhid); } \\
\text { - Menghindari hal- } \\
\text { hal yang merusak } \\
\text { keimanan kepada } \\
\text { Allah SWT } \\
\text { (syirik). }\end{array}$ & $\begin{array}{l}\text { Ceramah dengan } \\
\text { power point, tanya } \\
\text { jawab, dan latihan } \\
\text { kelompok }\end{array}$ \\
\hline 02 & & $\begin{array}{l}\text { a. Pembuktian } \\
\text { Wujud Allah dari } \\
\text { Perspektif } \\
\text { Filsafat Islam dan } \\
\text { Sains Modern } \\
\text { b. Perbanding-an } \\
\text { Agama-agama } \\
\text { (Yudaisme, } \\
\text { Kristen, dan } \\
\text { Islam) }\end{array}$ & $\begin{array}{l}\text { Memahami } \\
\text { argumentasi } \\
\text { perihal } \\
\text { keberadaan-Nya, } \\
\text { dan membedakan } \\
\text { akidah Islam dari } \\
\text { teologi agama- } \\
\text { agama samawi } \\
\text { lain }\end{array}$ & $\begin{array}{l}\text { - Memaparkan } \\
\text { bukti-bukti wujud } \\
\text { Allah, baik dari } \\
\text { sudut pandang } \\
\text { filsafat Islam } \\
\text { maupun sains } \\
\text { modern; } \\
\text { - Membedakan } \\
\text { antara akidah } \\
\text { Islam dan konsep } \\
\text { teologi agama- } \\
\text { agama samawi } \\
\text { lainnya }\end{array}$ & $\begin{array}{l}\text { Ceramah dengan } \\
\text { power point, tanya } \\
\text { jawab, dan latihan } \\
\text { kelompok. } \\
\text { Penyimpul-an. }\end{array}$ \\
\hline 03 & $\begin{array}{l}\text { Konsepsi } \\
\text { Islam } \\
\text { tentang } \\
\text { Manusia }\end{array}$ & $\begin{array}{l}\text { a. Hakikat Manusia, } \\
\text { serta Persamaan } \\
\text { dan Perbedaan- } \\
\text { nya dengan } \\
\text { Makhluk- } \\
\text { makhluk lain } \\
\text { b. Kedudukan dan } \\
\text { Tujuan } \\
\text { Penciptaan } \\
\text { Manusia }\end{array}$ & $\begin{array}{l}\text { Memahami } \\
\text { konsepsi manusia } \\
\text { menurut Islam, } \\
\text { tujuan penciptaan- } \\
\text { nya, fungsi dan } \\
\text { peran serta } \\
\text { tanggung } \\
\text { jawabnya sebagai } \\
\text { khalifah dan } \\
\text { hamba Allah, dan } \\
\text { meyakini } \\
\text { kebenaran konsep } \\
\text { manusia menurut } \\
\text { Islam }\end{array}$ & $\begin{array}{l}\text { - Menjelaskan } \\
\text { tentang konsep } \\
\text { manusia menurut } \\
\text { Islam; } \\
\text { - Mendeskripsi-kan } \\
\text { potensi positif } \\
\text { dan negatif } \\
\text { manusia; } \\
\text { - Menjelaskan } \\
\text { akibat yang } \\
\text { ditimbulkan dari } \\
\text { potensi negatif } \\
\text { manusia; } \\
\text { - Mengidentifika-si } \\
\text { persamaan dan } \\
\text { perbedaan } \\
\text { manusia dengan } \\
\text { makhluk lain; } \\
\text { - Menjelaskan } \\
\text { hubungan fungsi } \\
\text { manusia sebagai } \\
\text { khalifah dan } \\
\text { hamba Allah; } \\
\text { - Menerapkan } \\
\text { konsep manusia } \\
\text { menurut Islam } \\
\text { dalam kehidupan } \\
\end{array}$ & $\begin{array}{l}\text { Diskusi kelompok } \\
\text { dan diskusi kelas }\end{array}$ \\
\hline 04 & $\begin{array}{l}\text { Hukum } \\
\text { Islam, }\end{array}$ & $\begin{array}{l}\text { a. Konsep Hukum } \\
\text { Islam }\end{array}$ & $\begin{array}{l}\text { Memahami } \\
\text { konsep hukum }\end{array}$ & $\begin{array}{l}\text { - Menjelaskan } \\
\text { konsep-konsep }\end{array}$ & $\begin{array}{l}\text { Ceramah dengan } \\
\text { power point, tanya }\end{array}$ \\
\hline
\end{tabular}




\begin{tabular}{|c|c|c|c|c|c|}
\hline & $\begin{array}{l}\text { Aspek dan } \\
\text { Dimensi- } \\
\text { nya }\end{array}$ & $\begin{array}{l}\text { b. Sumber Hukum } \\
\text { Islam } \\
\text { c. Prinsip Hukum } \\
\text { Islam }\end{array}$ & $\begin{array}{l}\text { Islam, sumber dan } \\
\text { prinsipnya }\end{array}$ & $\begin{array}{l}\text { dan prinsip- } \\
\text { prinsip hukum } \\
\text { Islam; } \\
\text { - Membedakan } \\
\text { kedudukan } \\
\text { berbagai sumber } \\
\text { hukum Islam (al- } \\
\text { Qur'an, hadis, } \\
\text { dan ijtihad); } \\
\text { - Memadukan pola } \\
\text { pikir tekstual dan } \\
\text { kontekstual } \\
\text { sebagai dasar } \\
\text { berinteraksi } \\
\text { dengan sumber } \\
\text { hukum Islam } \\
\text { dalam kehidupan } \\
\text { sehari-hari; } \\
\text { - Menunjukkan } \\
\text { perbedaan antara } \\
\text { sunnahyang } \\
\text { bermuatan hukum } \\
\text { (tasyri'iyyah) dan } \\
\text { tidak bermuatan } \\
\text { hukum (ghairu } \\
\text { tasyri'iyah). }\end{array}$ & $\begin{array}{l}\text { jawab, dan latihan } \\
\text { kelompok }\end{array}$ \\
\hline 05 & & $\begin{array}{l}\text { a. Hukum Islam } \\
\text { dalam Struktur } \\
\text { Perundang- } \\
\text { undangan di } \\
\text { Indonesia } \\
\text { b. Perbanding-an } \\
\text { Mazhab }\end{array}$ & $\begin{array}{l}\text { Mengaitkan } \\
\text { hukum Islam } \\
\text { dengan struktur } \\
\text { perundang- } \\
\text { undangan di } \\
\text { Indonesia, dan } \\
\text { mengarifi adanya } \\
\text { perbedaan } \\
\text { pendapat dalam } \\
\text { memahami } \\
\text { hukum Islam }\end{array}$ & $\begin{array}{l}\text { - Mendeskripsikan } \\
\text { keterkaitan antara } \\
\text { hukum Islam dan } \\
\text { sistem } \\
\text { perundang- } \\
\text { undangan di } \\
\text { Indonesia; } \\
\text { - Menjelaskan } \\
\text { sebab-sebab } \\
\text { terjadinya } \\
\text { perbedaan } \\
\text { pendapat dalam } \\
\text { Islam; } \\
\text { - Mewujudkan } \\
\text { sikap saling } \\
\text { menghargai } \\
\text { pendapat di } \\
\text { antara sesama } \\
\text { umat Islam }\end{array}$ & $\begin{array}{l}\text { Diskusi kelompok, } \\
\text { diskusi kelas, dan } \\
\text { penyimpul-an }\end{array}$ \\
\hline 06 & $\begin{array}{l}\text { Etika, } \\
\text { Moral, dan } \\
\text { Akhlak } \\
\text { dalam } \\
\text { Perspektif } \\
\text { Islam,serta } \\
\text { Peranan- } \\
\text { nya dalam } \\
\text { Pembina- } \\
\text { an Masya- } \\
\text { rakat }\end{array}$ & $\begin{array}{l}\text { a. Pengertian Etika, } \\
\text { Moral, dan } \\
\text { Akhlak } \\
\text { b. Karakteristik } \\
\text { Akhlak Islam } \\
\text { c. Proses } \\
\text { Pembentukan } \\
\text { Akhlak } \\
\text { d. Ruang Lingkup } \\
\text { Akhlak Islam } \\
\text { e. Hubungan } \\
\text { Tasawuf dengan } \\
\text { Akhlak }\end{array}$ & $\begin{array}{l}\text { Memahami dan } \\
\text { menghayati } \\
\text { akhlak Islam, } \\
\text { tasawuf, serta } \\
\text { peranannya dalam } \\
\text { pembinaan } \\
\text { masyarakat, dan } \\
\text { menerapkan } \\
\text { akhlak Islam } \\
\text { dalam kehidupan }\end{array}$ & $\begin{array}{l}\text { - Menjelaskan } \\
\text { konsep etika, } \\
\text { moral, dan } \\
\text { akhlak; } \\
\text { - Membandingkan } \\
\text { perbedaan konsep } \\
\text { etika, moral, dan } \\
\text { akhlak; } \\
\text { - Mengidentifikasi } \\
\text { karakteristik } \\
\text { akhlak Islam; } \\
\text { - Mendeskripsikan } \\
\text { proses }\end{array}$ & $\begin{array}{l}\text { Ceramah dengan } \\
\text { power point, tanya } \\
\text { jawab, dan latihan } \\
\text { kelompok. } \\
\text { Penyimpul-an. }\end{array}$ \\
\hline
\end{tabular}




\begin{tabular}{|c|c|c|c|c|c|}
\hline & & $\begin{array}{l}\text { f. Peranan Akhlak } \\
\text { dalam Pembinaan } \\
\text { Masyarakat }\end{array}$ & & $\begin{array}{l}\text { pembentukan } \\
\text { akhlak; } \\
\text { - Mengidentifikasi } \\
\text { ruang lingkup } \\
\text { akhlak; } \\
\text { - Menjelaskan } \\
\text { hubungan antara } \\
\text { akhlak dengan } \\
\text { tasawuf; } \\
\text { - Berakhlak mulia } \\
\text { dalam kehidupan } \\
\text { sehari-hari }\end{array}$ & \\
\hline 07 & $\begin{array}{l}\text { Kebudaya- } \\
\text { an dan } \\
\text { peradab-an } \\
\text { Islam: } \\
\text { antara } \\
\text { Sejarah } \\
\text { Masa } \\
\text { Silam dan } \\
\text { Harapan } \\
\text { Masa } \\
\text { Depan }\end{array}$ & $\begin{array}{l}\text { a. Konsep } \\
\text { Kebudayaan dan } \\
\text { Peradaban dalam } \\
\text { Islam } \\
\text { b. Karakteristik } \\
\text { Kebudayaan dan } \\
\text { Peradaban Islam } \\
\text { c. Periodisasi } \\
\text { Sejarah } \\
\text { Kebudayaan dan } \\
\text { Peradaban Islam } \\
\text { d. Pasang-Surut } \\
\text { Kebudayaan dan } \\
\text { Peradaban Islam } \\
\text { e. Masjid dan } \\
\text { Madrasah } \\
\text { Sebagai Pusat } \\
\text { Kebudayaan dan } \\
\text { Peradaban Islam } \\
\text { f. Nilai-Nilai Islam } \\
\text { dalam } \\
\text { Kebudayaan } \\
\text { Indonesia }\end{array}$ & $\begin{array}{l}\text { Memahami } \\
\text { konsep } \\
\text { kebudayaan dan } \\
\text { peradaban Islam, } \\
\text { karakteristik, } \\
\text { perkembang-an, } \\
\text { serta pasang } \\
\text { surutnya sebagai } \\
\text { titik-tolak } \\
\text { menumbuh-kan } \\
\text { kesadaran dan } \\
\text { spirit baru } \\
\text { pentingnya } \\
\text { membangun } \\
\text { kebudayaan dan } \\
\text { peradaban Islam }\end{array}$ & $\begin{array}{l}\text { - Menjelaskan } \\
\text { konsep } \\
\text { kebudayaan dan } \\
\text { peradaban Islam, } \\
\text { karakteristik, } \\
\text { perkembangan, } \\
\text { serta pasang } \\
\text { surutnya; } \\
\text { - Membedakan } \\
\text { konsep } \\
\text { kebudayaan dan } \\
\text { peradaban Islam } \\
\text { dari berbagai } \\
\text { perspektif; } \\
\text { - Mempertahankan } \\
\text { nilai-nilai budaya } \\
\text { Islam sebagai } \\
\text { bagian dari } \\
\text { implementasi } \\
\text { ajaran Islam; } \\
\text { - Memprakarsai } \\
\text { penerapan nilai- } \\
\text { nilai budaya } \\
\text { Islam dalam } \\
\text { konteks } \\
\text { kehidupan sehari- } \\
\text { hari; } \\
\text { - Mendorong } \\
\text { tumbuhnya } \\
\text { kesadaran baru } \\
\text { akan pentingnya } \\
\text { membangun } \\
\text { kebudayaan dan } \\
\text { peradaban Islam; } \\
\text { - Merekonstruksi } \\
\text { spirit masa } \\
\text { keemasan } \\
\text { peradaban Islam } \\
\text { sebagai titik-tolak } \\
\text { merekayasa masa } \\
\text { depan peradaban } \\
\text { Islam yang } \\
\text { gemilang }\end{array}$ & $\begin{array}{l}\text { Diskusi kelompok, } \\
\text { diskusi kelas, dan } \\
\text { penyimpul-an }\end{array}$ \\
\hline 08 & \multicolumn{5}{|c|}{ UJIAN TENGAH SEMESTER (UTS) } \\
\hline 09 & $\begin{array}{l}\text { Masyara- } \\
\text { kat } \\
\text { Madani, }\end{array}$ & $\begin{array}{r}\text { a. Sejarah dan } \\
\text { Pemaknaan } \\
\text { Masyarakat }\end{array}$ & $\begin{array}{l}\text { Memahami } \\
\text { konsep dan } \\
\text { persyaratan }\end{array}$ & $\begin{array}{l}\text { - Menjelaskan } \\
\text { sejarah dan } \\
\text { konsep }\end{array}$ & $\begin{array}{l}\text { Ceramah dengan } \\
\text { power point, tanya } \\
\text { jawab. }\end{array}$ \\
\hline
\end{tabular}




\begin{tabular}{|c|c|c|c|c|c|}
\hline & \multirow[t]{2}{*}{$\begin{array}{l}\text { Rekon- } \\
\text { struksi } \\
\text { Kehidup- } \\
\text { an Islami } \\
\text { yang Ideal }\end{array}$} & $\begin{array}{l}\text { Madani } \\
\text { b. Masyarakat } \\
\text { Madani dalam } \\
\text { Perspektif Islam }\end{array}$ & $\begin{array}{l}\text { masyarakat } \\
\text { madani dalam } \\
\text { perspektif Islam }\end{array}$ & $\begin{array}{l}\text { masyarakat } \\
\text { madani dalam } \\
\text { perspektif Islam; } \\
\text { - Menguraikan } \\
\text { persyaratan } \\
\text { menuju } \\
\text { terbentuknya } \\
\text { masyarakat } \\
\text { madani }\end{array}$ & \\
\hline 10 & & $\begin{array}{l}\text { a. Persyaratan } \\
\text { Menuju } \\
\text { Masyarakat } \\
\text { Madani } \\
\text { b. Peluang dan } \\
\text { Tantangan } \\
\text { Menuju } \\
\text { Masyarakat } \\
\text { Madani }\end{array}$ & $\begin{array}{l}\text { Memahami upaya } \\
\text { umat Islam dalam } \\
\text { mewujudkanmasy } \\
\text { arakat madani }\end{array}$ & $\begin{array}{l}\text { - Menganalisis } \\
\text { peluang dan } \\
\text { tantangan menuju } \\
\text { masyarakat } \\
\text { madani; } \\
\text { - Mendorong } \\
\text { terbentuknya } \\
\text { struktur } \\
\text { komunitas yang } \\
\text { berdasar pada } \\
\text { konsep } \\
\text { masyarakat } \\
\text { madani } \\
\end{array}$ & $\begin{array}{l}\text { Diskusi kelompok, } \\
\text { diskusi kelas, dan } \\
\text { penyimpul-an. }\end{array}$ \\
\hline 11 & $\begin{array}{l}\text { Respons } \\
\text { Islam } \\
\text { terhadap } \\
\text { Politik, } \\
\text { Demokra- } \\
\text { si, dan } \\
\text { HAM }\end{array}$ & $\begin{array}{l}\text { a. Pengertian Politik } \\
\text { Islam } \\
\text { b. Prinsip-prinsip } \\
\text { Dasar dan Cita- } \\
\text { cita Politik Islam } \\
\text { c. Prinsip-prinsip } \\
\text { Politik Luar } \\
\text { Negeri dalam } \\
\text { Islam }\end{array}$ & $\begin{array}{l}\text { Memahami dan } \\
\text { melaksa-nakan } \\
\text { sistem politik } \\
\text { yang sesuai } \\
\text { dengan ajaran } \\
\text { Islam, serta } \\
\text { mampu } \\
\text { membedakan-nya } \\
\text { dari sistem-sistem } \\
\text { politik lain }\end{array}$ & $\begin{array}{l}\text { - Mengklasifikasi } \\
\text { aliran-aliran } \\
\text { politik dalam } \\
\text { Islam; } \\
\text { - Mendeskripsikan } \\
\text { pandangan Islam } \\
\text { tentang politik; } \\
\text { - Menggali konsep } \\
\text { pemerintahan } \\
\text { dalam Islam; } \\
\text { - Mengklasifikasi } \\
\text { aliran-aliran } \\
\text { politik dalam } \\
\text { Islam; } \\
\text { - Mendeskripsikan } \\
\text { pandangan Islam } \\
\text { tentang politik; } \\
\text { - Menggali konsep } \\
\text { pemerintahan } \\
\text { dalam Islam; }\end{array}$ & $\begin{array}{l}\text { Ceramah dengan } \\
\text { power point, tanya } \\
\text { jawab. }\end{array}$ \\
\hline 12 & & $\begin{array}{l}\text { a. Demokrasi dalam } \\
\text { Islam } \\
\text { b. Hak dan } \\
\text { Kewajiban Asasi } \\
\text { Manusia Menurut } \\
\text { Islam }\end{array}$ & $\begin{array}{l}\text { Memahami dan } \\
\text { melaksanakan } \\
\text { model demokrasi } \\
\text { yang sesuai } \\
\text { dengan ajaran } \\
\text { Islam, serta } \\
\text { mengerti hak-hak } \\
\text { dan kewajiban- } \\
\text { kewajiban, baik } \\
\text { sebagai warga } \\
\text { masyarakat } \\
\text { maupun sebagai } \\
\text { seorang Muslim }\end{array}$ & $\begin{array}{l}\text { - Mengidentifikasi } \\
\text { prinsip-prinsip } \\
\text { demokrasi yang } \\
\text { sesuai dengan } \\
\text { ajaran Islam; } \\
\text { - Menerapkan } \\
\text { prinsip ijma', } \\
\text { syura, dan } \\
\text { ijtihadsebagai } \\
\text { implementasi dari } \\
\text { demokrasi Islam; } \\
\text { - Menganalisis } \\
\text { konsep HAM } \\
\text { menurut Islam } \\
\text { dan versi Barat; } \\
\text { - Melaksanakan }\end{array}$ & $\begin{array}{l}\text { Diskusi kelompok, } \\
\text { diskusi kelas, dan } \\
\text { penyimpul-an. }\end{array}$ \\
\hline
\end{tabular}




\begin{tabular}{|c|c|c|c|c|c|}
\hline & & & & $\begin{array}{l}\text { kewajiban } \\
\text { sebagai warga } \\
\text { masyarakat dan } \\
\text { sebagai seorang } \\
\text { Muslim; } \\
\text { - Menghormati dan } \\
\text { memenuhi hak- } \\
\text { hak orang lain }\end{array}$ & \\
\hline 13 & \multirow[t]{2}{*}{$\begin{array}{l}\text { Reformula } \\
\text { si konsep } \\
\text { jihad } \\
\text { menuju } \\
\text { Islam } \\
\text { moderat }\end{array}$} & $\begin{array}{l}\text { a. Pengertian Jihad } \\
\text { dan Radikalisme } \\
\text { Umat Beragama } \\
\text { b. Landasan dan } \\
\text { Macam-Macam } \\
\text { Jihad } \\
\text { c. Latar Belakang } \\
\text { Radikalisme } \\
\text { Agama } \\
\end{array}$ & $\begin{array}{l}\text { Memahami secara } \\
\text { benar konsep } \\
\text { jihad }\end{array}$ & $\begin{array}{l}\text { - Menjelaskan } \\
\text { konsep jihad dan } \\
\text { radikalisme } \\
\text { agama }\end{array}$ & $\begin{array}{l}\text { Ceramah dengan } \\
\text { power point, tanya } \\
\text { jawab. }\end{array}$ \\
\hline 14 & & $\begin{array}{l}\text { a. Bentuk dan } \\
\text { Dampak } \\
\text { Radikalisme } \\
\text { Umat Beragama } \\
\text { b. Upaya } \\
\text { Menanggulangi } \\
\text { Radikalisme } \\
\text { Umat Beragama } \\
\text { c. Muslim Moderat }\end{array}$ & $\begin{array}{l}\text { Memahami secara } \\
\text { mendalam } \\
\text { persoalan } \\
\text { radikalisme } \\
\text { agama, serta } \\
\text { berperilaku } \\
\text { sebagai muslim } \\
\text { moderat }\end{array}$ & $\begin{array}{l}\text { - Berperilaku } \\
\text { sebagai muslim } \\
\text { moderat dalam } \\
\text { kehidupan } \\
\text { bermasyarakat }\end{array}$ & $\begin{array}{l}\text { Diskusi kelompok, } \\
\text { diskusi kelas, dan } \\
\text { penyimpul-an. }\end{array}$ \\
\hline 15 & $\begin{array}{l}\text { Perempu- } \\
\text { an dalam } \\
\text { Islam, } \\
\text { menafsir- } \\
\text { kan } \\
\text { kembali } \\
\text { doktrin } \\
\text { agama } \\
\text { tentang } \\
\text { perempu- } \\
\text { an }\end{array}$ & $\begin{array}{l}\text { a. Pengertian dan } \\
\text { Sejarah } \\
\text { Feminisme } \\
\text { b. Jenis-jenis } \\
\text { Feminisme } \\
\text { c. Respons Masyara } \\
\text { d. Konsep Islam } \\
\text { tentang } \\
\text { Perempuan } \\
\text { e. Pandangan Islam } \\
\text { terhadap } \\
\text { Feminisme }\end{array}$ & $\begin{array}{l}\text { Memahami } \\
\text { konsep feminisme } \\
\text { dan pandangan } \\
\text { Islam tentang } \\
\text { perempuan dan } \\
\text { feminisme, } \\
\text { meyakini } \\
\text { pandangan Islam } \\
\text { tentang } \\
\text { perempuan dan } \\
\text { feminisme dan } \\
\text { menerapkannya } \\
\text { dalam kehidupan } \\
\text { sehari-hari }\end{array}$ & $\begin{array}{l}\text { - Menjelaskan } \\
\text { konsep } \\
\text { feminisme dan } \\
\text { pandangan Islam } \\
\text { tentang } \\
\text { perempuan dan } \\
\text { feminisme; } \\
\text { - Meyakini } \\
\text { kebenaran } \\
\text { pandangan Islam } \\
\text { tentang } \\
\text { perempuan dan } \\
\text { feminisme; } \\
\text { - Bersikap dan } \\
\text { berprilaku sesuai } \\
\text { dengan } \\
\text { pandangan Islam } \\
\text { tentang } \\
\text { perempuan dan } \\
\text { feminisme. }\end{array}$ & $\begin{array}{l}\text { Diskusi kelompok, } \\
\text { diskusi kelas, dan } \\
\text { penugasan (take } \\
\text { home) }\end{array}$ \\
\hline 16 & & UJI & N AKHIR SEMI & TER (UAS) & \\
\hline
\end{tabular}

2. Uji Pakar terhadap Draft Buku Ajar diselenggarakan 21 Juni dan 28 Juni 2010. PAI Setiap bab dipresentasikan secara terbuka

Dengan memperhatikan silabus dan kerangka bahan ajar, materi buku ajar PAI dengan pendekatan integratifinterkonektif ini disusun sebagaimana terlampir (lihat lampiran). untuk selanjutnya dikritisi dan diberi masukan oleh sejawat. Dosen-dosen yang terlibat dalam kegiatan uji pakar tersebut sebanyak 12 orang, yakni Prof. Dr. H.M. Huda, AY, M.Pd., Drs. H. A. Manan Idris, Adapun penyempurnaan draft buku ajar itu dilakukan melalui "seminar kolegial" intern dosen PAI UM yang Drs. H. M. Dahlan Ridlwan, Drs. H. Muchsin Zain, Drs. H. M. Thoha AR, S.Pd., M.Pd., Dra. Hj. Jazimah, S.Pd., 
Dra. Hj. Siti Malikhah Towaf, M.A., Ph.D., Khoirul Adib, S.Pd., M.A., A. Munjin Nasih, S.Pd., M.Ag., Syafaat, S.Ag., M.Ag., Lilik Nur Kholidah, S.Pd., M.Pd.I., Ach. Sultoni, S.Ag., M.Pd.I.

Beberapa saran yang disampaikan para pakar sehubungan dengan perbaikan bahan ajar yang disusun ini, antara lain: (a) bahan ajar ini perlu diperkaya dengan latihan-latihan praktis sehingga nantinya dapat meningkatkan kebermaknaan materi bagi para mahasiswa dalam kehidupan sehari-hari; (b) beberapa pokok bahasan perlu dipertajam fokusnya, seperti bab Etika, Moral, dan Akhlak dalam Perspektif Islam, dan bab Kebudayaan dan Peradaban Islam: Antara Sejarah Masa Lampau dan Harapan Masa Depan.

Tahap selanjutnya pasca uji pakar melalui forum seminar kolegial adalah uji coba produk yang melibatkan mahasiswa sebagai pengguna.

\section{Uji Coba Produk}

Terkait dengan uji coba produk, materi yang akan diujicobakan berupa draftbuku ajar yang telah mendapatkan masukan dari para pakar (melalui uji pakar). Pokok bahasan yang diujicobakan akan ditentukan sesuai kondisi dan kebutuhan. Yang menjadi objek sasaran uji coba ini adalah mahasiswa Universitas Negeri Malang (UM) yang akan menempuh matakuliah PAIpada semester genap tahun ajaran 2009-2010(dari Fakultas MIPA, Fakultas Teknik, Fakultas Ilmu Pendidikan, Fakultas Ilmu Keolahragaan, Fakultas Ekonomi, Fakultas Ilmu Sosial, dan Fakultas Sastra).Pelibatan keseluruhan fakultas (tujuh fakultas) di UM ini dimaksudkan agar diperoleh respons, baik dari mahasiswa yang menekuni bidang keilmuan eksakta (MIPA dan teknik), keilmuan sosial (ilmu pendidikan, keolahragaan, dan ekonomi), maupun humaniora (sastra). Sehingga diharapkan nantinya akan diperoleh input yang benarbenar komprehensif, tidak hanya sebatas dari para pakar (expert), namun juga dari pengguna (user)-nya.

Setelah uji coba rampung dilaksanakan, objek sasaran uji coba (baca: mahasiswa) dimintamengisi kuesioner yang berisi pertanyaan seputar pendapat mereka tentang materi yang diujicobakan. Data yang dikumpulkan dalam uji coba ini digunakan untuk menyempurnakan materi/bahan ajar yang diujicobakan.

Dari total 350 kuisener yang disebarkan di tujuh fakultas (masingmasing 50 kuisener), diperoleh varian jawaban sebagai berikut. Pertama, terkait dengan keterbacaan (tingkat kesulitan) buku PAI ini, diperoleh jawaban: $71 \%$ menyatakan "mudah dipelajari", 25\% menyatakan "cukup sulit, tetapi dapat dipelajari secara bertahap", dan 4\% menyatakan "sangat sulit dipelajari". Kedua, terkait dengan materi buku PAI beserta instruksinya, diperoleh jawaban: $75 \%$ menyatakan "mudah dimengerti", $17 \%$ menyatakan "kadang mudah dimengerti, dan kadang tidak", dan 8\% menyatakan "sangat sulit dimengerti". Ketiga, terkait dengan kesalahan isi dan editorial, didapatkan varian jawaban: $15 \%$ menyatakan "tidak ada", $83 \%$ menyatakan "ada tetapi sangat sedikit", dan 2\% menyatakan "sangat banyak". Keempat, terkait dengan alur penyajian (struktur buku), diperoleh jawaban: $65 \%$ menyatakan "sangat bagus", 23\% menyatakan "cukup bagus", dan 12\% menyatakan "kurang bagus". Kelima, terkait dengan kesesuaian materi buku PAI sebagai kajian keislaman interdisipliner, diperoleh jawaban: $87 \%$ menyatakan "sudah sesuai", $8 \%$ menyatakan "baru sebagiannya saja", dan 5\% menyatakan "kurang sesuai dengan fungsi yang diharapkan".Keenam, terkait dengan kemampuan buku PAI untuk memenuhi kebutuhan pemelajar, didapatkan jawaban: $79 \%$ menyatakan "sudah memuaskan", 17\% menyatakan "memuaskan", dan 4\% menyatakan 
"kurang memuaskan". Ketujuh, terkait dengan jumlah latihan dalam buku PAI, didapatkan jawaban: 69\% menyatakan "proporsional", 27\% menyatakan "kadang terlalu banyak, kadang terlalu sedikit", dan 4\% menyatakan "sangat kurang". Kedelapan, terkait dengan kemenarikan materi, didapatkan jawaban: $65 \%$ menyatakan "sangat menarik", $32 \%$ menyatakan "cukup menarik", dan 3\% menyatakan "kurang menarik".

Dari paparan data kuesioner di atas, diketahui bahwa mayoritas pengguna (baca: mahasiswa) yang menjadi objek ujicoba produk buku ajar PAI yang dikembangkan dengan integratifinterkonektif ini cukup puas dengan performansinya, baik dari sisi substansi maupun teknik penyajiannya.

\section{SIMPULAN}

Pengembangan bahan ajar PAI dengan pendekatan integratif-interkonektif ini bertumpu pada kajian pustaka dan hasil eksplorasi kurikulum, buku ajar PAI sebelumnya (Reorientasi Pendidikan Islam: Menuju Pengembangan Kepribadian Insan Kamil), dan pelaksanaan perkuliahan Matakuliah Pengembangan Kepribadian (PAI) di UM.

Hasil pengembangan meliputi: (1) silabus pengembangan bahan ajar PAI dengan pendekatan integratif-interkonektif [interdisipliner]; (2) bahan ajar perkuliahan PAI dengan pendekatan integratif-interkonektif [interdisipliner]. Tiap pokok bahasan mencakup uraian tentang kompetensi dasar, indikator pencapaian, bahasan inti, dan latihan.

Hasil uji pakar adan uji coba produk menunjukkan bahwa bahan ajar ini cukup efektif untuk dijadikan sebagai salah satu alternatif materi perkuliahan PAI mengingat terobosan pendekatannya dalam mengkaji topik-topik keislaman secara interdisipliner.

\section{DAFTAR PUSTAKA}

Abdullah, M. A. (2001). Al-Ta'wil al-'Ilmi:
Ke Arah Perubahan Paradigma Penafsiran Kitab Suci. Al-Jami'ah, 39(2).

Abdullah, M. A. (2006). Islamic Studies di Perguruan Tinggi: Pendekatan Integratif-Interkonektif. Yogyakarta: Pustaka Pelajar.

Abdullah, M. A. (2007). Islamic Studies dalam Paradigma IntegrasiInterkoneksi: Sebuah Antologi. Yogyakarta: Penerbit SUKA Press.

Baum, G. (1999). Agama Dalam BayangBayang Irelativisme: Sebuah Analisis Sosiologi Pengetahuan Karl Mannheim Tentang Sintesa Kebenaran Historis-Normatif. Ter. Achmad Mustajib et. al. Yogyakarta: PT. Tiara Wacana.

Kuntowijoyo. (2007). Islam sebagai Ilmu. Yogyakarta: Tiara Wacana.

Mansoer, H. (2006). Strategi Pengembangan MPK. Indonesia: Direktorat Ketenagaan, Direktorat Jenderal Pendidikan Tinggi, Departemen Pendidikan Nasional.

Rahman, F. (1982). Islam and Modernity: Transformation of an Intellectual Tradition. Chicago and London: The University of Chicago Press.

Shahrur, M. (1990). Al-Kitab wa alQur'an: Qira'ah Mu'ashirah. Dimashq: t.p. 